\title{
An aubasidan-like $\beta$-glucan produced by Aureobasidium pullulans in Thailand
}

\author{
Pongtharin Lotrakul $^{\mathrm{a}, *}$, Pantakarn Unhapattaratitikul ${ }^{\mathrm{a}}$, Tosak Seelanan ${ }^{\mathrm{b}}$, Sehanat Prasongsuk $^{\mathrm{a}}$, \\ Hunsa Punnapayak ${ }^{\mathrm{a}}$ \\ a Plant Biomass Utilization Research Unit, Department of Botany, Faculty of Science, \\ Chulalongkorn University, Bangkok 10330 Thailand \\ b Plants of Thailand Research Unit, Department of Botany, Faculty of Science, Chulalongkorn University, \\ Bangkok 10330 Thailand
}

*Corresponding author, e-mail: pongtharin.1@chula.ac.th

\begin{abstract}
The nutrient assimilation profile of two non-pullulan-producing strains of Aureobasidium pullulans (NRRL 58539 and NRRL 58543) isolated in Thailand was investigated. Similar nutrient assimilation was observed between both strains and the pullulan-producing A. pullulans NRRL 58560. All three strains weakly assimilated methyl- $\alpha$-D-glucoside and lactose. For the exopolysaccharide (EPS) production, NRRL 58539 and NRRL 58543 preferred $\mathrm{NaNO}_{3}$ as the sole nitrogen source. Enzyme sensitivity assays, infrared spectroscopy, and nuclear magnetic resonance analyses of the EPSs revealed a broad structural similarity to aubasidan and not to pullulan. This is the first report of an aubasidan-like $\beta$-glucan produced by A. pullulans in Thailand.
\end{abstract}

KEYWORDS: exopolysaccharide, pullulan, molecular phylogenetics, $\beta$-tubulin

\section{INTRODUCTION}

Aureobasidium pullulans (De Bary) Arnoud is a saprophytic black yeast commonly found worldwide in a wide range of habitats, such as leaf surfaces, painted walls, African deserts, marine environs and even glacial and subglacial ice ${ }^{1-5}$. A. pullulans is of biotechnological interest since it produces a biodegradable poly- $\alpha-1,6$-maltotriose based exopolysaccharide (EPS) called pullulan. In addition to pullulan, an EPS with a different structure called aubasidan, a $\beta$-1,3-D-glucan with $\beta$-1,6-branches to $\alpha-1,4$ side chains, has been reported in some $A$. pullulans strains ${ }^{6}$. Based on the EPS structure, nutritional physiology and some molecular features, these aubasidan-producing strains of $A$. pullulans were placed in the variety aubasidani ${ }^{6}$. However, multilocus phylogenetic analysis placed the type strain of $A$. pullulans var. aubasidani (CBS 100524) within the same clade as the pullulan-producing A. pullulans var. pullulans, and thus the ability to produce aubasidan was suggested to be strain-dependent rather than variety-dependent ${ }^{4}$.

In 2006, two strains of non-pullulan-producing Aureobasidium sp. (NRRL 58539 and NRRL 58543) were separately isolated from different areas in Thailand. Multilocus DNA sequence analysis suggested that these two strains were probably not $A$. pullulans since they were grouped together in a separate clade from the other $A$. pullulans strains ${ }^{5,7}$. In this study, the nutrient assimilation profile and the preferred nitrogen source for EPS production of these Aureobasidium strains were investigated. The EPS structure was also studied using enzyme sensitivity assays, infrared spectroscopy and nuclear magnetic resonance spectroscopy. The results obtained from this study will shed light on the structural diversity of EPSs produced by Aureobasidium in Thailand.

\section{MATERIALS AND METHODS}

A. pullulans NRRL 58539 (CU26, from Nakhon Ratchasima, Thailand), A. pullulans NRRL 58543 (CU30, from Prachuap Khiri Khan, Thailand), A. pullulans NRRL 58560 (NRM2, from Nakhon Ratchasima, Thailand), and A. pullulans var. aubasidani CBS 100524 (NRRL 58013) were obtained from the Microbial Genomics and Bioprocessing Research Unit, US Department of Agriculture, Peoria, Illinois, USA. All yeast strains were maintained on yeast malt agar at room temperature $\left(30 \pm 2{ }^{\circ} \mathrm{C}\right)$. Short-term stock cultures were prepared using yeast malt broth (YMB) containing 15\% (v/v) glycerol and kept at $-20^{\circ} \mathrm{C}$. Freeze-dried cultures were also made for long-term storage at $4{ }^{\circ} \mathrm{C}$.

For the nutrient assimilation test, seed culture was 
prepared by growing each Aureobasidium strain in YMB at room temperature with agitation $(150 \mathrm{rpm})$ for 1 day. The cell number was counted using a haemacytometer and adjusted to $2.5 \times 10^{7}$ cells $/ \mathrm{ml}$. One $\mathrm{ml}$ of the seed culture was then transferred to mineral medium containing each test carbon (equivalent to $10 \mathrm{~g} \mathrm{C} / \mathrm{l}$ ) and nitrogen (equivalent to $1 \mathrm{~g} \mathrm{~N} / \mathrm{l}$ ) source. $\left(\mathrm{NH}_{4}\right)_{2} \mathrm{SO}_{4}$ was added as a nitrogen source for the carbon assimilation test whereas glucose was used as carbon source for the nitrogen assimilation test. Each culture was grown in $50 \mathrm{ml}$ medium in a $250-\mathrm{ml}$ Erlenmeyer flask at room temperature with agitation $(150 \mathrm{rpm})$ for five days. Growth was measured as the cell density. Experiments were carried out in triplicate.

It has been reported that the pullulan-producing strains of A. pullulans prefer ammonium as the sole nitrogen source for their EPS production, whereas that of the aubasidan-producing strains is nitrate ${ }^{6,8,9}$. Hence the effect of nitrogen source on the EPS production by NRRL 58539, NRRL 58543 and NRRL 58560 was investigated using Production Medium as previously described ${ }^{3}$. $\left(\mathrm{NH}_{4}\right)_{2} \mathrm{SO}_{4}$ and $\mathrm{NaNO}_{3}$ were used as the sole nitrogen source (equivalent to $0.13 \mathrm{~g}$ $\mathrm{N} / \mathrm{l}$ ) whereas sucrose was used as the sole carbon source $(5 \% \mathrm{w} / \mathrm{v}$, equivalent to $21.03 \mathrm{~g} \mathrm{C/l})$. Cultures were incubated at room temperature with agitation (150 rpm) for 9 days. Cells were removed by centrifugation at $5200 \mathrm{~g}$ for $15 \mathrm{~min}$. EPS was precipitated from the supernatant by adding 2 volumes of $95 \%(\mathrm{v} / \mathrm{v})$ ethanol as previously described ${ }^{2}$. The precipitated EPS was oven dried $\left(60^{\circ} \mathrm{C}\right)$, weighed, ground to fine powder and then kept in a desiccator at room temperature for further studies. Experiments were carried out in triplicate. Differences among the EPS yields obtained from these media were statistically compared using Student's $t$-test.

To elucidate the structure of the EPS produced by NRRL 58539 and NRRL 58543, enzyme sensitivity test and Fourier transform infrared spectroscopy (FT-IR) were performed. Enzyme sensitivity test was carried out following the protocol of Leathers et $\mathrm{al}^{10}$. EPS was separately digested by four different enzymes, each at $0.1 \mathrm{U} / \mathrm{ml}$ : pullulanase (from Klebsiella pneumoniae, Sigma, USA), $\alpha$-amylase (from Aspergillus oryzae, Sigma, USA), glucoamylase (from Aspergillus niger, Sigma, USA), and $\beta$-glucanase (from Trichoderma longibrachiatum, Sigma, USA), under the optimal conditions recommended by the respective manufacturer. Released reducing sugars were measured using the dinitrosalicylic acid (DNS) method ${ }^{11}$. Sensitivity to the specific enzyme digestion (\%) was separately calculated in comparison to the value obtained from each control enzyme-digested substrate under otherwise identical conditions (pullulanase on pullulan (Sigma, USA) as substrate, $\alpha$-amylase and glucoamylase on soluble starch (Scharlau Chemie S.A., Spain) as substrate, and $\beta$-glucanase on aubasidan (produced by the strain CBS 100524) as substrate). Experiments were carried out in triplicate.

FT-IR was performed as previously described ${ }^{3}$. Ground EPS was mixed with $\mathrm{KBr}$ at a (w/w) ratio of 1:100. Infrared spectra were measured by Fourier Transform Infrared Spectrometer (PerkinElmer (Spectrum One), USA) at Scientific and Technological Research Equipment Centre, Chulalongkorn University. The average of 16 scans at a resolution of $4 \mathrm{~cm}^{-1}$ was performed per sample.

For ${ }^{1} \mathrm{H}-\mathrm{NMR}$ analysis, each EPS sample was dissolved in $\mathrm{D}_{2} \mathrm{O}$ to the final concentration of $0.05 \mathrm{mg} / \mathrm{ml}$. The ${ }^{1} \mathrm{H}-\mathrm{NMR}$ spectra was obtained at $50^{\circ} \mathrm{C}$ using a Varian Inova-500 NMR System equipped with a CP/MAS solid state probe and nano probe, operating at $500 \mathrm{MHz}$.

The phylogenetic placements of NRRL 58539 and NRRL 58543 were assessed using the ITS15.8S rRNA (with partial $3^{\prime}$-18S rRNA and $5^{\prime}$-ITS2 sequences, GenBank accession codes: EU719513 and EU719518) and partial $\beta$-tubulin encoding DNA fragment sequences (EU719407 and EU719412) ${ }^{5}$ in comparison with the published sequences ${ }^{4}$ obtained from the NCBI GenBank database (accession codes for ITS/ $\beta$-tubulin) for $A$. pullulans var. pullulans $\mathrm{CBS}$ 146.30 (FJ150902/FJ157871), CBS 584.75 (FJ150906 /FJ157869), and CBS 701.76 (FJ150907/FJ157865), A. pullulans var. aubasidani CBS 100524 (FJ150905/ FJ157867), var. melanogenum CBS 123.37 (FJ150881 /FJ157852), CBS 621.80 (FJ150885/FJ157859), and CBS 105.22 (FJ150886/FJ157858), var. namibiae CBS 147.97 (FJ150875/FJ157863), and var. subglaciale EXF-2479 (FJ150893/FJ157877), EXF-2491 (FJ150894/FJ157880), and EXF-2481 (FJ150895/ FJ157878), plus the corresponding sequences from Selenophoma mahoniae CBS 388.92 (FJ150872/ FJ157874) ${ }^{4}$, which were used as the outgroup. Sequence alignment was carried out manually using GeneDoc $^{12}$.

The maximum parsimony analysis was conducted by branch and bound search with branch support from bootstrap analysis of 500 replications using PAUP* $4.0 \mathrm{~b} 10^{13}$. In addition, Bayesian inference (BI) was performed in MRBAYES version 3.2.1 ${ }^{14}$. Model of nucleotide substitution was determined by JMODELTEST version 0.1.1 ${ }^{15}$. MRENT version $2.2^{16}$ was used to annotate the phylogenetic tree. 
Table 1 Effect of the nitrogen source on EPS production levels by Aureobasidium pullulans NRRL 58539, NRRL 58543, and NRRL 58560.

\begin{tabular}{lccr}
\hline $\mathrm{C}$ and $\mathrm{N}$ sources in production medium & \multicolumn{2}{c}{ EPS yield $(\mathrm{g} / \mathrm{l})^{\dagger}$} \\
\cline { 2 - 4 } & NRRL 58539 & NRRL 58543 & NRRL 58560 \\
\hline Sucrose $+\left(\mathrm{NH}_{4}\right)_{2} \mathrm{SO}_{4}$ & $0.64 \pm 0.00^{\ddagger}$ & $1.12 \pm 0.01$ & $16.25 \pm 0.04$ \\
Sucrose $+\mathrm{NaNO}_{3}$ & $0.85 \pm 0.00$ & $3.21 \pm 0.01$ & $13.21 \pm 0.09$ \\
\hline
\end{tabular}

'Mean \pm one standard deviation derived from three replicates.

\$ The mean values in each column were statistically different (Student's $t$-test; $P<0.05$ ).

Table 2 Sensitivity towards specific enzyme digestion of the EPS produced by Aureobasidium pullulans NRRL 58539 and NRRL 58543.

\begin{tabular}{lcccc}
\hline EPS/source & \multicolumn{3}{c}{ Sensitivity (\%) } \\
\cline { 2 - 4 } & Pullulanase $^{\mathrm{a}}$ & $\alpha$-Amylase $^{\mathrm{b}}$ & Glucoamylase $^{\mathrm{c}}$ & $\beta_{\text {-Glucanase }}^{\mathrm{d}}$ \\
\hline EPS/NRRL 58539 & $12.2 \pm 0.6^{\mathrm{e}}$ & $2.5 \pm 0.3$ & $3.5 \pm 1.0$ & $88.6 \pm 4.4$ \\
EPS/NRRL 58543 & $13.5 \pm 0.6$ & $3.5 \pm 0.3$ & $\mathrm{ND}^{\mathrm{f}}$ & $91.4 \pm 4.4$ \\
Aubasidan/CBS 100524 & $12.1 \pm 0.0$ & $1.8 \pm 0.7$ & $4.3 \pm 0.4$ & $100.0^{\mathrm{d}}$ \\
Pullulan/NRRL 58560 & $77.7 \pm 0.3$ & $3.5 \pm 0.2$ & $52.5 \pm 0.3$ & ND \\
Pullulan/Sigma (USA) & $100.0^{\mathrm{a}}$ & $2.8 \pm 0.3$ & $52.9 \pm 0.7$ & ND \\
Pullulan/Hayashibara (Japan) & $97.0 \pm 0.3$ & $2.9 \pm 0.4$ & $44.8 \pm 0.9$ & ND \\
Soluble starch & $12.0 \pm 0.3$ & $100.0^{\mathrm{b}}$ & $100.0^{\mathrm{c}}$ & ND \\
\hline
\end{tabular}

${ }^{\text {a }}$ Compared to the value obtained from pullulan (Sigma, USA) digested by pullulanase.

${ }^{\mathrm{b}}$ Compared to the value obtained from soluble starch (Scharlau Chemie S.A., Spain) digested by $\alpha$-amylase.

${ }^{c}$ Compared to the value obtained from soluble starch (Scharlau Chemie S.A., Spain) digested by glucoamylase.

${ }^{\mathrm{d}}$ Compared to the value obtained from aubasidan (produced by CBS 100524) digested by $\beta$-glucanase.

e Mean \pm one standard deviation derived from three replicates.

${ }^{f} \mathrm{ND}$, Not detectable.

\section{RESULTS}

The nutrient assimilation profiles of the NRRL 58539 and NRRL 58543 strains were the same as each other and similar to that of the pullulan-producing NRRL 58560. All 3 strains strongly assimilated L-arabinose, D-fructose, D-galactose, D-glucose, D-mannose, D-xylose, D-maltose, D-sucrose, D-mannitol, glycerol, $\left(\mathrm{NH}_{4}\right)_{2} \mathrm{SO}_{4}, \mathrm{NaNO}_{3}$, and peptone whereas they weakly assimilated D-arabinose, L-sorbose, D-cellobiose, $\alpha$-cellulose, soluble starch, and ethanol. However, both NRRL 58539 and NRRL 58543 exhibited a stronger and weaker assimilation of D-mannitol and glycine, respectively, than those of NRRL 58560. Interestingly, in contrast to A. pullulans var. aubasidani CBS $100524^{6}$, both these strains and A. pullulans NRRL 58560 could weakly assimilate methyl- $\alpha$-Dglucoside and $\beta$-lactose (data not shown).

It was found that both NRRL 58539 and NRRL 58543 produced greater EPS yields in the medium containing $\mathrm{NaNO}_{3}$, attaining an EPS yield of $0.85 \pm 0.00$ and $3.21 \pm 0.01 \mathrm{~g} / \mathrm{l}$, respectively, while the pullulan-producing NRRL58560 produced the greatest amount of EPS at $16.25 \pm 0.04 \mathrm{~g} / \mathrm{l}$ in the medium containing $\left(\mathrm{NH}_{4}\right)_{2} \mathrm{SO}_{4}$ (Table 1).

The EPS from both NRRL 58539 and NRRL 58543 were found to be resistant to digestion by pullulanase (12\% and $14 \%$ sensitivity, respectively, compared to that of pullulan) and glucoamylase (4\% and not detectable, respectively, compared to that of starch) (Table 2). In contrast, the two EPSs from NRRL 58539 and NRRL 58543 were sensitive to $\beta$-glucanase digestion, somewhat similar to aubasidan from CBS 100524, but dissimilar to pullulan. All EPSs tested were not digested to any significant level by $\alpha$-amylase.

FT-IR spectra of the EPSs produced by NRRL 58539 and NRRL 58543 were similar to that of the aubasidan produced by CBS 100524 (Table 3), where all three spectra revealed the presence of the $\beta$-configuration peak, which, albeit at slightly different wavenumbers, agrees with the previously reported peak of aubasidan ${ }^{6}$ at $890 \mathrm{~cm}^{-1}$. An absence of the $\alpha$-glycosidic linkage ${ }^{6}$ at $\lambda=850 \mathrm{~cm}^{-1}$ was also observed. In contrast, pullulan showed the characteristic peak for $\alpha$-glycosidic linkage but not $\beta$-configuration.

Structural analysis of the EPSs from NRRL 58539 and NRRL 58543 using ${ }^{1} \mathrm{H}$ nuclear magnetic reso- 
Table 3 FT-IR wavenumbers $\left(\mathrm{cm}^{-1}\right)$ of the different EPSs tested in this study.

\begin{tabular}{lcccccc}
\hline Assignments & $\begin{array}{c}\text { NRRL 58539 } \\
\text { EPS }\end{array}$ & $\begin{array}{c}\text { NRRL 58543 } \\
\text { EPS }\end{array}$ & $\begin{array}{c}\text { CBS 100524 } \\
\text { aubasidan }\end{array}$ & $\begin{array}{c}\text { NRRL 58560 } \\
\text { pullulan }\end{array}$ & $\begin{array}{c}\text { Sigma } \\
\text { pullulan }\end{array}$ & $\begin{array}{c}\text { Hayashibara } \\
\text { pullulan }\end{array}$ \\
\hline O-H & 3425.57 & 3426.80 & 3428.40 & 3433.23 & 3433.76 & 3434.16 \\
C-H & 2933.66 & 2933.02 & 2928.09 & 2928.37 & 2928.32 & 2928.95 \\
O-C-O & 1618.84 & 1618.56 & 1634.77 & 1637.00 & 1637.47 & 1641.63 \\
C-OH & 1321.69 & 1385.05 & 1373.92 & 1370.35 & 1365.61 & 1366.83 \\
C-O-C & 1162.94 & 1157.59 & 1152.45 & 1155.43 & 1154.97 & 1155.90 \\
C-O & 1042.40 & 1038.99 & 1036.00 & 1020.16 & 1020.18 & 1019.57 \\
$\beta$-configuration & 879.61 & 887.49 & 891.88 & - & - & - \\
$\alpha$-configuration & - & - & - & 849.16 & 847.95 & 847.94 \\
\hline
\end{tabular}

nance spectroscopy $\left({ }^{1} \mathrm{H}-\mathrm{NMR}\right)$ was reported previously $^{5}$, and the absence of the peaks representing $\alpha-1,6-$ and $\alpha-1,4$-configuration, in comparison to a commercial pullulan, was noted. The experiment was repeated in this study with aubasidan produced by CBS 100524 included for comparison. Multiple peaks representing the $\beta-1,3$ and $\beta-1,6$ configurations were detected in both the EPSs from NRRL 58539 (chemical shifts for $\beta-1,3 / \beta-1,6)$ (4.513 and $4.497 \mathrm{ppm} /$ $4.289,4.278,4.272$, and $4.266 \mathrm{ppm})$ and NRRL 58543 (4.528, 4.514, and $4.498 \mathrm{ppm} / 4.274,4.265,4.258$, and $4.250 \mathrm{ppm}$ ) and aubasidan (4.513 and $4.497 \mathrm{ppm} /$ $4.265,4.257,4.249$, and $4.241 \mathrm{ppm})$. Two peaks representing the $\alpha$-anomeric configurations, assignable to 4-linked or terminal $\alpha-1,6-\mathrm{D}-$ Gluc $p^{17}$, were observed in aubasidan (5.095 and $5.088 \mathrm{ppm}$ ) whereas several small peaks, ranging from 5.149 to $5.045 \mathrm{ppm}$, were visible in the EPSs from NRRL 58539 and NRRL 58543 (data not shown).

After sequence alignment was carried out, the data matrices of ITS and $\beta$-tubulin sequences of 498 bp and 406 bp, respectively, were obtained (TreeBASE submission ID 12967).

The selected ITS1-5.8S rRNA (with partial ITS2 sequence) fragment revealed 36 parsimonious informative/ 3 polymorphic sites, while that for the $\beta$-tubulin fragment sequence was $81 / 31$ and for the concatenated sequences was $117 / 34$, respectively.

Separate analyses of the ITS1-5.8S rRNA (with partial ITS2 sequence) and $\beta$-tubulin fragment sequences by both MP and BI analyses yielded similar results for the four analyses, as determined visually for the obtained tree topologies (data not shown). Firstly, strains from the same variety (A. pullulans var. pullulans, subglaciale, melanogenum, namibiae and NRRL58539/NRRL58543) formed monophyletic groups with high MP bootstrap and BI posterior probability support, except that in the MP analysed ITS tree the monophyly of $A$. pullulans var. melanogenum lacked bootstrap support. Secondly,

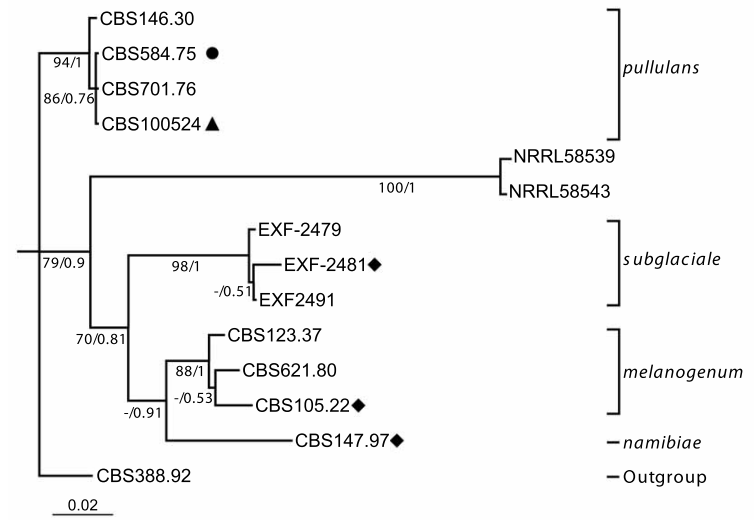

Fig. 1 The consensus tree from BI (MrBayes) based on the 904 bp of combined ITS and $\beta$-tubulin partial sequences. Branch supports are shown under each node for MP bootstrap values (when $>50 \%$ )/BI posterior probabilities. Circles: the ex-neotype strain of $A$. pullulans var. pullulans; triangles: the ex-type strain of A. pullulans var. aubasidani; diamonds: the ex-type strain of the designated variety. GenBank accession codes for the partial ITS/ $\beta$-tubulin sequences are given in the phylogenetic section of materials and methods. The scale bar shown represents $0.02 \mathrm{nu}-$ cleotide changes.

the (NRRL58539/NRRL58543) subclade did not nest within any clade of the analysed $A$. pullulans varieties. Thirdly, although the relationships among the four subclades of the A. pullulans varieties and the (NRRL58539/NRRL58543) subclade were uncertain, the (NRRL58539/NRRL58543) subclade was clearly nested within A. pullulans in both trees. Results from the combined analysis of the concatenated ITS and $\beta$-tubulin sequences were similar to those from the separate analyses of the two partial DNA sequences by both MP and BI analysis, with the BI derived tree shown as a representative example in Fig. 1. Most nodes had high MP bootstrap support and high BI 
posterior probabilities. With $79 \%$ bootstrap support and $0.9 \mathrm{BI}$ posterior probabilities, it was clear that the (NRRL58539/NRRL58543) subclade was the sister group of the varieties melanogenum, namibiae, and subglaciale.

\section{DISCUSSION}

Unlike A. pullulans var. pullulans, the ex-type strain of A. pullulans var. aubasidani CBS 100524 was reportedly unable to assimilate methyl- $\alpha$-D-glucoside and lactose and had nitrate as the preferred nitrogen source for EPS production instead of ammonium ions ${ }^{6}$. However, multilocus DNA sequence analysis grouped these physiologically different strains together, suggesting that they belonged to the same variety and so the ability to produce aubasidan was possibly straindependent ${ }^{4}$. This suggestion was further supported by the observation that some A. pullulans strains had genes for both pullulan and $\beta$-glucan synthesis in their genome $^{18}$. Moreover, when cultivated in media with high nitrate concentration, some pullulan-producing A. pullulans strains were reported to produce mixture of pullulan and various $\beta$-glucans ${ }^{19}$. In this study, the non-pullulan producing NRRL 58539 and NRRL 58543 strains had a similar nutrient assimilation profile to those of other pullulan-producing strains in that they were able to assimilate methyl- $\alpha$-D-glucoside and lactose, albeit weakly. Previous multilocus DNA sequence analyses suggested that both strains were not A. pullulans var. pullulans because they grouped in a different clade ${ }^{5,7}$. However, representative strains of the three varieties of A. pullulans, (var. melanogenum, subglaciale, and namibae) were not included in those analyses. In this study, a combined ITS and $\beta$-tubulin DNA sequence analysis was performed with the representative strains of all $A$. pullulans varieties included, and the results suggested that both NRRL 58539 and NRRL 58543 are likely to be a new variety of A. pullulans.

From the EPS structural analysis, in terms of its sensitivity to enzyme digestion and FT-IR and ${ }^{1} \mathrm{H}-\mathrm{NMR}$ analyses, a reasonably strong resemblance was found between the EPSs produced by NRRL 58539 and NRRL 58543 and aubasidan, with all three EPSs having $\beta$-glycosidic linkages and the absence of major $\alpha$-glycosidic bonds. However, slight differences in the FT-IR spectra wavenumbers and the ${ }^{1} \mathrm{H}-\mathrm{NMR}$ chemical shifts among these EPSs and aubasidan suggested the presence of minor structural variations, most likely in the side chains, supported by the small differences observed in their sensitivities to digestion by the different enzymes. Based on these findings, it can be concluded that the EPSs produced by NRRL 58539 and NRRL 58543 were aubasidanlike $\beta$-glucan.

Several reports suggested that type of nitrogenous substrate and its concentration in the medium crucially affected the yield and structure of EPSs produced by $A$. pullulans ${ }^{19-22}$. When both NRRL 58539 and NRRL 58543 were individually grown in a culture media containing either ammonium or nitrate at different concentrations, EPS with appearance similar to pullulan had not been detected (data not shown). Results from FT-IR analysis confirmed the absence of pullulan in the EPSs produced by these two strains. Without gene and genome analysis, it is difficult to determine whether NRRL 58539 and NRRL 58543 lack genes for pullulan synthesis or possess the genes that do not express due to the significant differences in genetic background between NRRL 58539/NRRL 58543 and another pullulan-producing strains ${ }^{5}$.

Beta-glucan derived from yeasts and mushrooms is known for its various biological activities such as mammal immune system enhancement ${ }^{23}$ and in vitro growth activation of probiotic bacteria ${ }^{24}$. It has been reported that $\beta-(1,3-1,6)$-glucan and aubasidan from A. pullulans could modulate immune system in dosedepending manner ${ }^{25,26}$. Although aubasidan has not been reported as a prebiotic agent, the EPS produced by NRRL 58543 was found to be able to enhance the growth of two probiotic bacteria, Lactobacillus acidophilus and Lactobacillus casei ${ }^{27}$. Hence it is of interest to further investigate the biological activity of these EPSs for their potential application in food and pharmaceutical industries.

During the last decade, a large number of isolates of $A$. pullulans have been isolated from different tropical habitats in various areas of Thailand ${ }^{1-3,5}$. Most of these strains produced pullulan with only a few exceptions, such as the strains NRRL 58539 and NRRL 58543. However, the structure of EPS produced from the NRRL 58539 and NRRL 58543 strains have not been characterized in previous reports $^{5,7}$. This study is the first report of aubasidan-like $\beta$-glucan-producing strains of $A$. pullulans isolated in Thailand.

Acknowledgements: The authors are thankful to the Ratchadaphiseksomphot Endowment Fund (CU-CLUSTER-FUND) for the Plant Biomass Utilization Research Unit, Department of Botany, Chulalongkorn University, and the Higher Education Research Promotion and National Research University Project of Thailand, Office of the Higher Education Commission (EN281B and CU56-EN07) for financial support. Valuable comments on the manuscript from Robert Butcher were appreciated. 


\section{REFERENCES}

1. Punnapayak H, Sudhadham M, Prasongsuk S, Pichayangkura S (2003) Characterization of Aureobasidium pullulans isolated from airborne spores in Thailand. J Ind Microbiol Biotechnol 30, 89-94.

2. Prasongsuk S, Sullivan RF, Kuhirun M, Eveleigh DE, Punnapayak H (2005) Thailand habitats as sources of pullulan-producing strains of Aureobasidium pullulans. World J Microbiol Biotechnol 21, 393-8.

3. Prasongsuk S, Berhow MA, Dunlap CA, Weisleder D, Leathers TD, Eveleigh DE, Punnapayak H (2007) Pullulan production by tropical isolates of Aureobasidium pullulans. J Ind Microbiol Biotechnol 34, 55-61.

4. Zalar P, Gostinčar C, de Hoog GS, Uršič V, Sudhadham M, Gunde-Cimerman N (2008) Redefinition of Aureobasidium pullulans and its varieties. Stud Mycol 61, 21-38.

5. Manitchotpisit P, Leathers TD, Peterson SW, Kurtzman CP, Li XL, Eveleigh DE, Lotrakul P, Prasongsuk S, et al (2009) Multilocus phylogenetic analyses, pullulan production and xylanase activity of tropical isolates of Aureobasidium pullulans. Mycol Res 113, 1107-20.

6. Yurlova NA, de Hoog GS (1997) A new variety of Aureobasidium pullulans characterized by exopolysaccharide structure, nutritional physiology and molecular features. Antonie Leeuwenhoek 72, 141-7.

7. Manitchotpisit P, Skory CD, Peterson SW, Price NPJ, Vermillion KE, Leathers TD (2012) Poly( $\beta$-L-malic acid) production by diverse phylogenetic clades of Aureobasidium pullulans. J Ind Microbiol Biotechnol 39, 125-32.

8. Badr-Eldin SM, El-Tayeb OM, El-Masry HG, Mohamad FHA, Abd El-Rahman OA (1994) Polysaccharide production by Aureobasidium pullulans: factors affecting polysaccharide formation. World J Microbiol Biotechnol 10, 423-6.

9. Thirumavalavan K, Manikkadan TR, Dhamasekar R (2009) Pullulan production from coconut by-products by Aureobasidium pullulans. Afr J Biotechnol 8, 254-8.

10. Leathers TD, Nofsinger GW, Kurtzman CP, Bothas RJ (1988) Pullulan production by color variant strains of Aureobasidium pullulans. J Ind Microbiol Biotechnol 3, 231-9.

11. Miller JH (1959) Use of dinitrosalicylic acid reagent for determination of reducing sugar. Anal Chem 31, 426-8.

12. Nicholas KB, Nicholas HB Jr, Deerfield DW II (1997) GeneDoc: Analysis and visualization of genetic variation. EMBnet.news 4, $\mathrm{Nr} 2,1-4$.

13. Swofford DL (2003) PAUP*. Phylogenetic Analysis Using Parsimony (*and Other Methods). Version 4. Sinauer Associates, Sunderland, Massachusetts.

14. Ronquist F, Teslenko M, van der Mark P, Ayres DL, Darling A, Höhna S, Larget B, Liu L, Suchard MA, Huelsenbeck JP (2012) MRBAYES 3.2: Efficient Bayesian phylogenetic inference and model selection across a large model space. Syst Biol 61, 539-42.
15. Posada D (2008) jModelTest: Phylogenetic model averaging. Mol Biol Evol 25, 1253-6.

16. Zuccon A, Zuccon D (2010) MrEnt v.2.2. Program distributed by the authors. http://www.mrent.org. Accessed 8 June 2012.

17. Dinadayala P, Sambou T, Daffe M, Lemassu A (2008) Comparative structural analyses of the $\alpha$-glucan and glycogen from Mycobacterium bovis. Glycobiology $\mathbf{1 8}$, 502-8.

18. Kang BK, Yang HJ, Choi NS, Ahn KH, Park CS, Yoon BD, Kim MS (2010) Production of pure $\beta$-glucan by Aureobasidium pullulans after pullulan synthase gene disruption. Biotechnol Lett 32, 137-42.

19. Zheng W, Campbell BS, McDougall BM, Seviour RJ (2008) Effects of melanin on the accumulation of exopolysaccharides by Aureobasidium pullulans grown on nitrate. Bioresour Tech 99, 7480-6.

20. Cheng K-C, Demirci A, Catchmark JM (2011) Pullulan: biosynthesis, production, and applications. Appl Microbiol Biotechnol 92, 29-44.

21. Cheng KC, Demirci A, Catchmark JM (2010) Enhanced pullulan production in a biofilm reactor by using response surface methodology. J Ind Microbiol Biotechnol 37, 587-94.

22. Cheng K-C, Demirci A, Catchmark JM, Puri VM (2011) Effects of initial ammonium ion concentration on pullulan production by Aureobasidium pullulans and its modelling. J Food Eng 103, 115-22.

23. Smiderle FR, Olsen LM, Carbonero ER, Baggio CH, Freitas CS, Marcon R, Santos ARS, Gorin PAJ, Iacomini M (2008) Anti-inflammatory and analgestic properties in a rodent model of a (1-3), (1-6)-linked $\beta$-glucan isolated from Pleurotus pulmonarius. Eur $J$ Pharmacol 597, 86-91.

24. Synytsya A, Mickova A, Synytsya A, Jablonsky I, Spevacek J, Erban V, Kovarikova E, Copikova J (2009) Glucans from fruit bodies of cultivated mushrooms Pleurotus ostreatus and Pleurotus eryngii: structure and potential prebiotic activity. Carbohydr Polymer 78, 548-56.

25. Suzuki T, Hosono A, Hachimura S, Suzuki T, Kaminogawa S (2006) Modulation of cytokine and immunoglobulin A release by beta-(1,3-1,6)-glucan from Aureobasidium pullulans strain 1A1. In: Iijima S, Nishijma K-I (eds) Animal Cell Technology: Basic \& Applied Aspects, Springer, The Netherlands. pp 369-75.

26. Dyakov YT (2007) Chapter 13 - General and specific aspects of plant and animal immunity. In: Dyakov YT, Dzhavakhiya VG, Corpel T (eds) Comprehensive and Molecular Phytopathology, Elsvier, The Netherlands. pp 351-64.

27. Unhapattaratitikul P (2012) Production of exopolysaccharide from a tropical strain of Aureobasidium pullulans and its film casting. MSc thesis, Chulalongkorn Univ. 